\title{
DYNAMIC TESTS ON A CONCRETE SLAB WITH A TUNED MASS DAMPER
}

\author{
Jorge Eliécer Campuzano Carmona ${ }^{1}$, Suzana Moreira Avila² ${ }^{2}$ Graciela N. Doz ${ }^{3}$ \\ ${ }^{1}$ UNB, University of Brasilia, Department of Civil Engineering, Brasília, Brazil. \\ ${ }^{2}$ UNB, University of Brasilia, Faculty of Gama FGA, Department of Civil Engineering, Brasília, Brazil. \\ ${ }^{3}$ UNB, University of Brasilia, Department of Civil Engineering, Brasilia, Brazil.
}

\begin{abstract}
Nowadays, structures became more slender and flexible due to lighter materials with great resistance, compared to traditional materials used in construction. This fact provides to structural systems with low natural frequencies. High amplitude vibrations can be experienced, when the structures are subjected to people walking, running, jumping, dancing, activities that are characterized by periodical low frequency forces. Various solutions can be taken, such as techniques to stiffen all the structure, which can result a non-economical solution and not practical. Other alternative that can be more economical and executable is to install tuned mass dampers (TMD) at the building structure, that vibrate out of phase with the main system, transferring the mechanical energy to the additional mass. In this work, excessive vibrations in concrete slabs are studied through testing a dynamic platform very flexible where it is installed a TMD. The tests simulate human activities such as walking, jumping or dancing. Vibrations amplitudes of the platform are compared with and without TMD installation, finding a good reduction on these amplitudes with this structural control device. The TMD designed has a dry friction mechanism to reduce the response of the additional mass, controlling excessive vibration caused by human activities in building floors. Keywords: Tuned Mass Damper, Damping, Modal Analysis, Frequency-Domain Analysis, Time-Domain Analysis, MAC
\end{abstract}

\section{Introduction.}

Nowadays, new structures are more and more slender and flexible with longer spans, presenting low natural vibration frequencies.

More flexible structures implicate on higher vibration amplitudes that are transmitted to people using these rooms affecting human activities such as feet and hands movements

To solve this problem on civil structures such as offices, commercial areas, gyms, dancing clubs, laboratories, theaters and footbridges, structural control devices such as tuned mass dampers (TMD) can be installed.

TMD are designed to have a fundamental frequency value near one of the main structure frequencies, in a way that a portion of the energy is transferred to the TMD reducing excessive vibrations. This type of damper has a good performance, reducing vertical and horizontal vibrations in real structures such as Millennium Bridge, London [1], Marina Bay Sands Hotel, Singapore [2], a Abandoibarra Footbridge, Spain [2], Rio Niterói Bridge, Rio de Janeiro, Brazil [3].

\section{TMD and main structure description.}

TMD was designed with ANSYS software [4], mass, damping and stiffness parameters were found out. Those parameters were set, tuning the damper to the main structure: a dynamic test platform with $6,1 \mathrm{~m}$ length and 4,9 $\mathrm{m}$ width and $0,1 \mathrm{~m}$ thickness [5] that presents a fundamental frequency of $3,32 \mathrm{~Hz}$, i.e. within the range of values of the characteristics frequencies values of walking, jumping and dancing: between 1,5 $\mathrm{Hz}$ and 5,5 $\mathrm{Hz}$ for first and second harmonic [6]. For obtaining these dynamic characteristics numerical and experimental studies were performed. On Table 1 it is presented the numeric modal analysis results with the three first natural frequencies of the platform.

Table 1. Numerical natural frequencies

\begin{tabular}{|c|c|}
\hline \multicolumn{2}{|c|}{ Numerical Study } \\
\hline Frequency 1 & $3.36 \mathrm{~Hz}$ \\
\hline Frequency 2 & $15.67 \mathrm{~Hz}$ \\
\hline Frequency 3 & $23.64 \mathrm{~Hz}$ \\
\hline
\end{tabular}

The numerical TMD optimal parameters were: vibrating mass $120 \mathrm{~kg}$, damping coefficient $360 \mathrm{Ns} / \mathrm{m}$ and stiffness $51000 \mathrm{~N} / \mathrm{m}$. With these optimal values it was constructed the TMD presented on Figure 1.
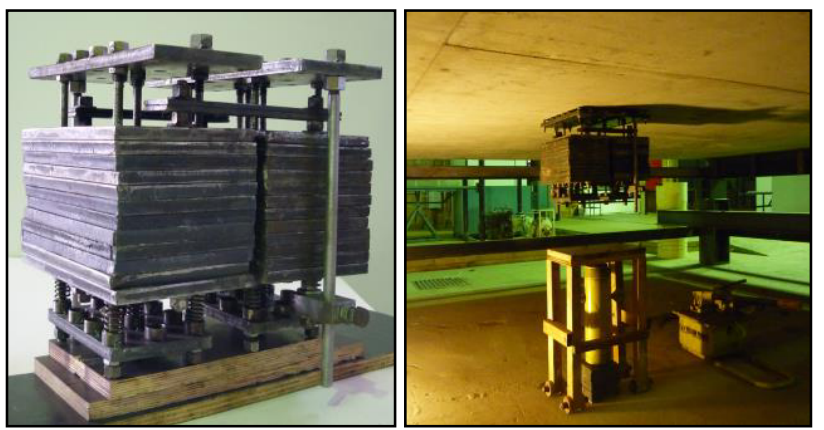

Figure 1. TMD attached to the dynamic platform with two vibrating mass sets.

georcam2003@hotmail.com avilas@unb.br graciela@unb.br 


\section{Experimental test descriptions}

To determine the first experimental natural frequencies of the platform, 4 tests were performed.

The instrumentation consisted of two piezoelectric accelerometers (PCB Piezotronics), one fixed in the center of the slab (node 41 - tests 1 and 4) or on the slab corner (node 20 - tests 2 and 3) and other mobile that changed position through the structure as shown in Figure 2 and Figure 3.

The accelerometers were connected to a signal processor ADS2000 that is connecter to a computer. The tests were performed exciting the slab on the platform center with impact produced by the drop heel for a second and letting the structure vibrate for 14 seconds. Acceleration records were processed by ARTeMIS software [7] and the first four modal shapes with corresponding frequencies were obtained (Table 2).

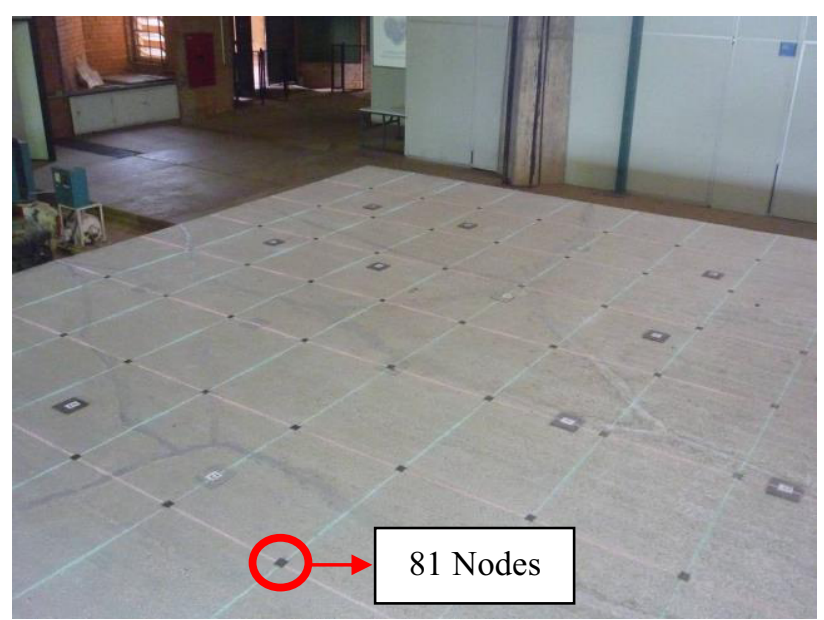

Figure 2. 81 node mesh to obtain acceleration records.

\begin{tabular}{|r|r|r|r|r|r|r|r|r|r|}
\hline 1 & 2 & 3 & 4 & 5 & 6 & 7 & 8 & 9 & \\
\hline 10 & 11 & 12 & 13 & 14 & 15 & 16 & 17 & 18 & \\
\hline 19 & 20 & 21 & 22 & 23 & 24 & 25 & 26 & 27 & \\
\hline 28 & 29 & 30 & 31 & 32 & 33 & 34 & 35 & 36 & \\
\hline 37 & 38 & 39 & 40 & 41 & 42 & 43 & 44 & 45 & \\
\hline 46 & 47 & 48 & 49 & 50 & 51 & 52 & 53 & 54 & \\
\hline 55 & 56 & 57 & 58 & 59 & 60 & 61 & 62 & 63 & \\
\hline 64 & 65 & 66 & 67 & 68 & 69 & 70 & 71 & 72 & \\
\hline 73 & 74 & 75 & 76 & 77 & 78 & 79 & 80 & 81 & \\
\hline & & & & & & & & & \\
\hline
\end{tabular}

Figure 3. Node numeration of the experimental mesh.
Table 2. Experimental frequencies of the four tests.

\begin{tabular}{|c|c|c|c|c|}
\hline Freq \# & Test 1 & Test 2 & Test 3 & Test 4 \\
\hline F1 & $3.42 \mathrm{~Hz}$ & $3.32 \mathrm{~Hz}$ & $3.32 \mathrm{~Hz}$ & $3.32 \mathrm{~Hz}$ \\
\hline F2 & $15.53 \mathrm{~Hz}$ & $15.14 \mathrm{~Hz}$ & $15.23 \mathrm{~Hz}$ & $15.33 \mathrm{~Hz}$ \\
\hline F3 & $23.24 \mathrm{~Hz}$ & $22.95 \mathrm{~Hz}$ & ----- & $23.05 \mathrm{~Hz}$ \\
\hline F4 & $85.25 \mathrm{~Hz}$ & $31.35 \mathrm{~Hz}$ & $51.76 \mathrm{~Hz}$ & $91.99 \mathrm{~Hz}$ \\
\hline F5 & ----- & $48.63 \mathrm{~Hz}$ & ----- & ---- \\
\hline
\end{tabular}

Figure 4 shows time history acceleration and Figure 5 this record Fourier transform indicating the first slab frequencies.

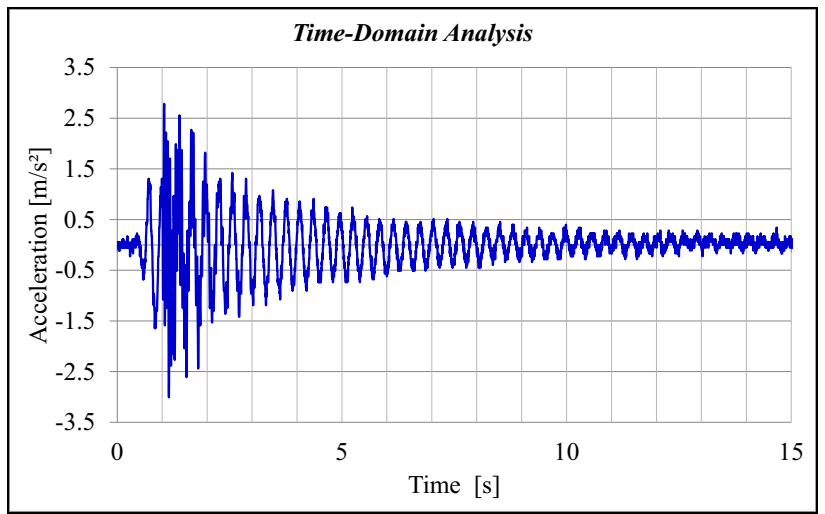

Figure 4. Time-history acceleration, Test 4.

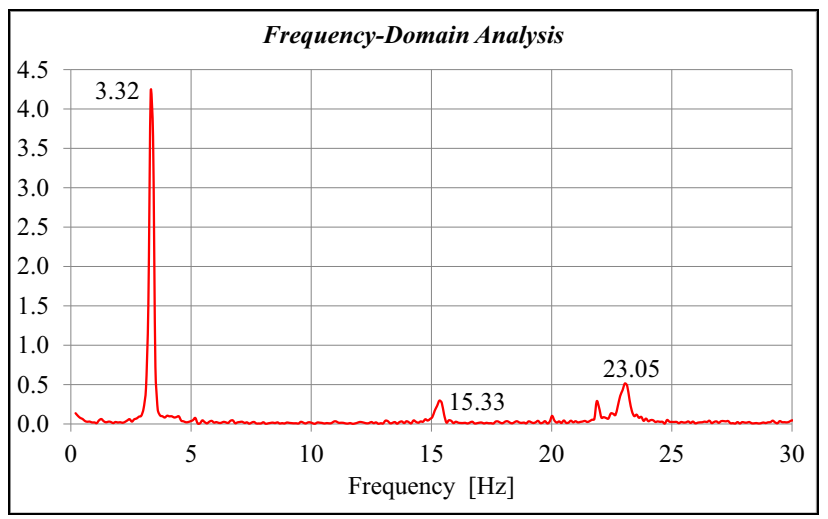

Figure 5. Frequency-Domain analysis, Test 4.

Table 3 present comparative results between numerical and experimental analysis for the three first natural frequencies of the structure.

Table 3. Comparative results between numerical and experimental analysis for the three first natural frequencies of the structure.

\begin{tabular}{|l|c|c|c|}
\cline { 2 - 4 } \multicolumn{1}{c|}{} & Numerical & Experimental & $\%$ error \\
\hline Frequency 1 & $3.36 \mathrm{~Hz}$ & $3.32 \mathrm{~Hz}$ & $1.19 \%$ \\
\hline Frequency 2 & $15.67 \mathrm{~Hz}$ & $15.33 \mathrm{~Hz}$ & $2.17 \%$ \\
\hline Frequency 3 & $23.64 \mathrm{~Hz}$ & $23.05 \mathrm{~Hz}$ & $2.50 \%$ \\
\hline
\end{tabular}


From Figure 6 to Figure 8 it is shown the three first mode shapes obtained through numerical simulation and experimental procedures, respectively.

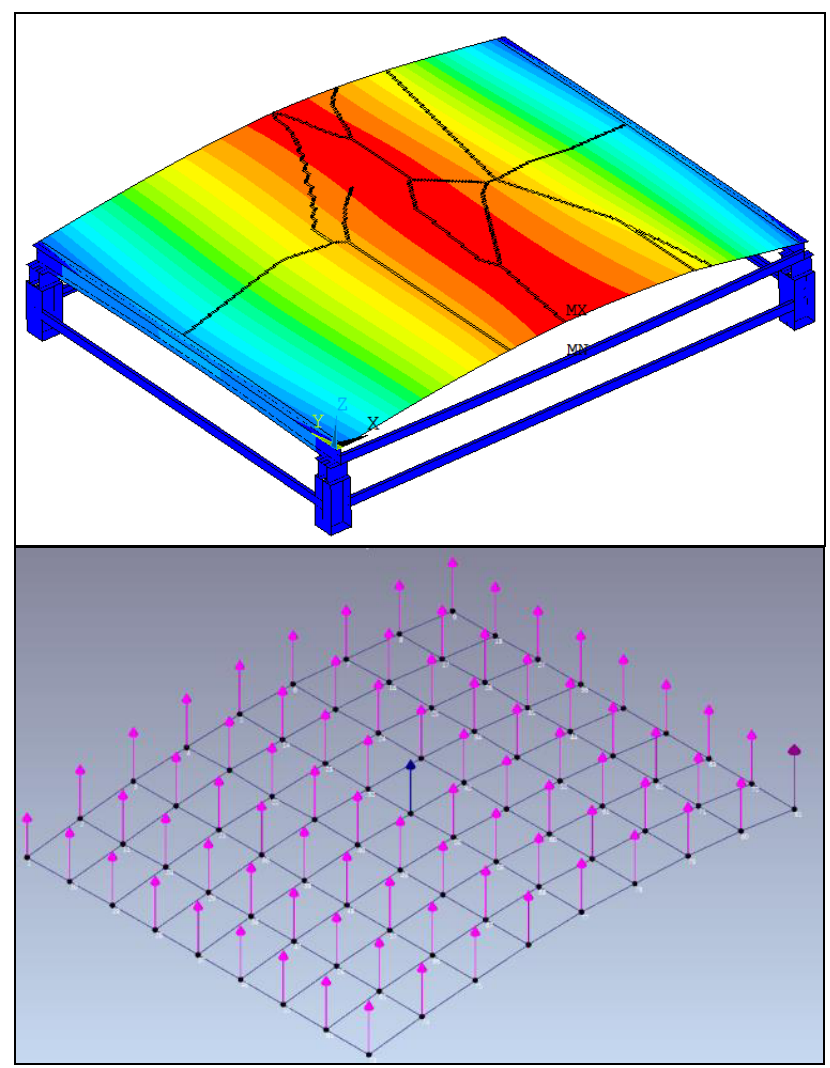

Figure 6. First modal shape numerical ANSYS[4] and experimental ARTeMIS[7].

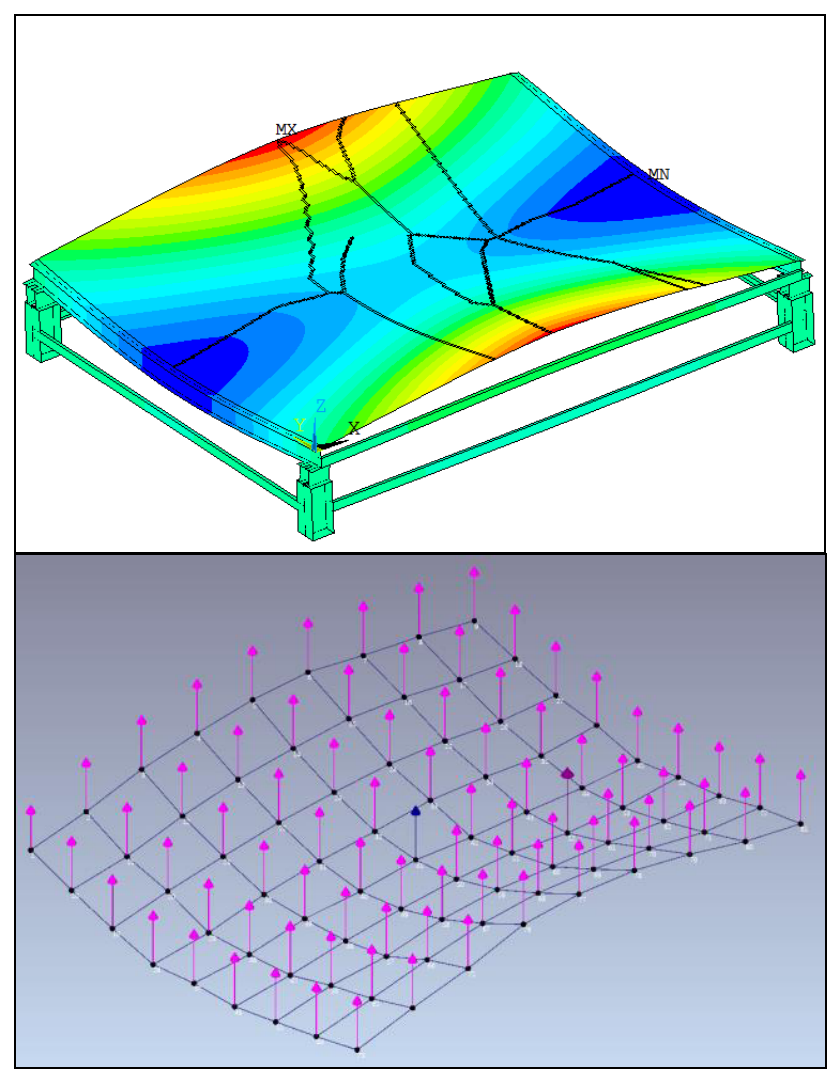

Figure 7. Second modal shape numerical ANSYS[4] and experimental ARTeMIS[7].

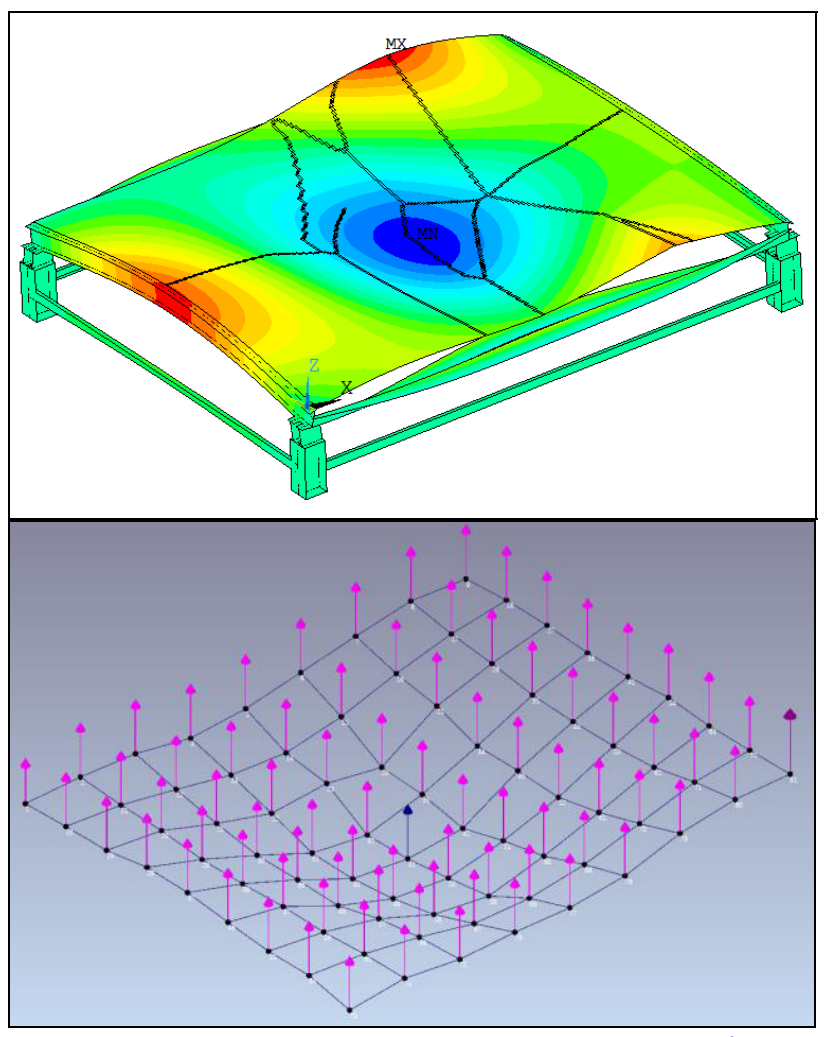

Figure 8. Third modal shape numerical ANSYS[4] and experimental ARTeMIS[7].

The three first experimental modal shapes obtained using ARTeMIS [7] are consistent with those obtained numerically with ANSYS [4].

From the experimental and numerical results it was performed a Modal Assurance Criterion $M A C$ study and the results are show on Figure 9 to Figure 12. These values are close to 1 for the first modal shape, this means that both the numerical values as the experimental values are mutually consistent. On the main diagonal of MAC matrix it is found out the combination of the three first modal shapes numerical and experimental, being more satisfactory the results for the first and second modes.

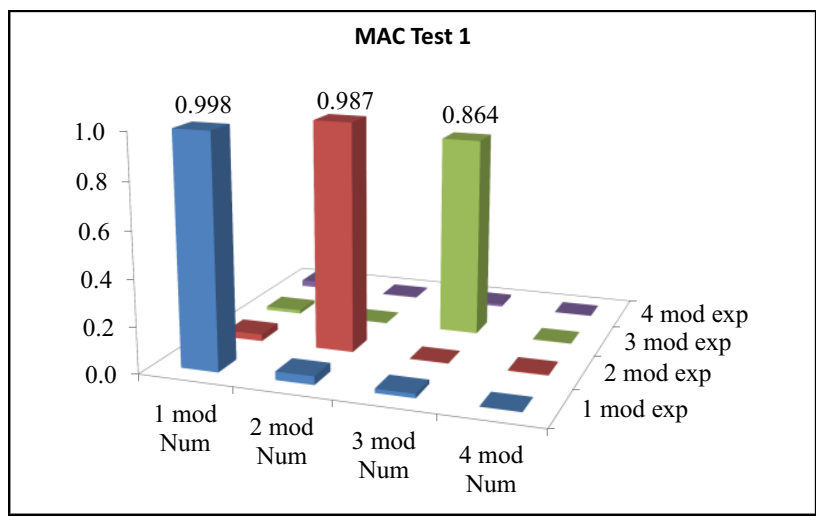

Figure 9. Modal assurance Criterion Test 1. 


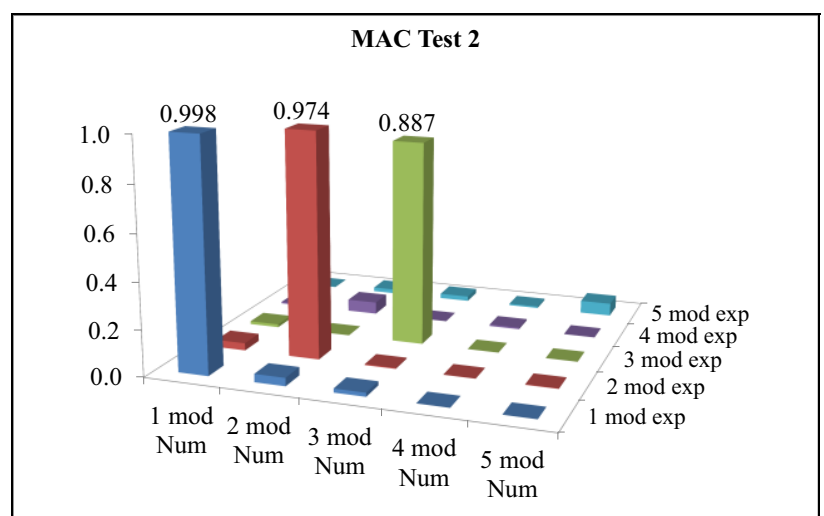

Figure 10. Modal assurance Criterion Test 2.

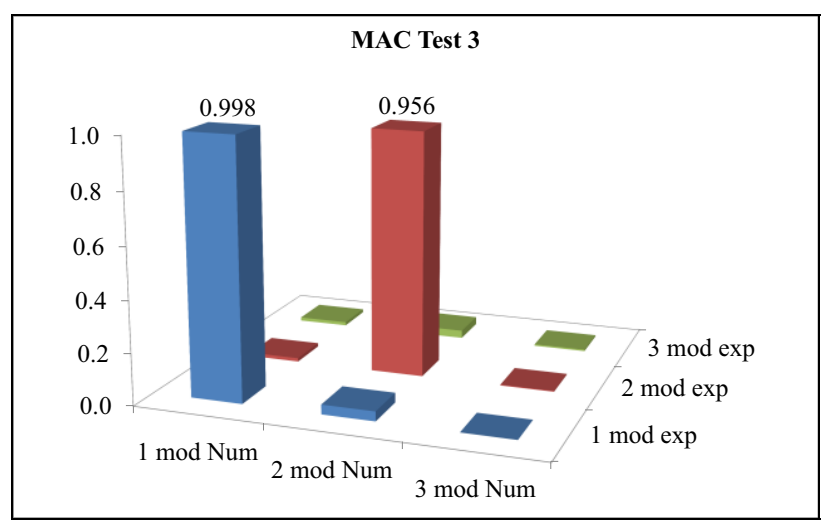

Figure 11. Modal assurance Criterion Test 3.

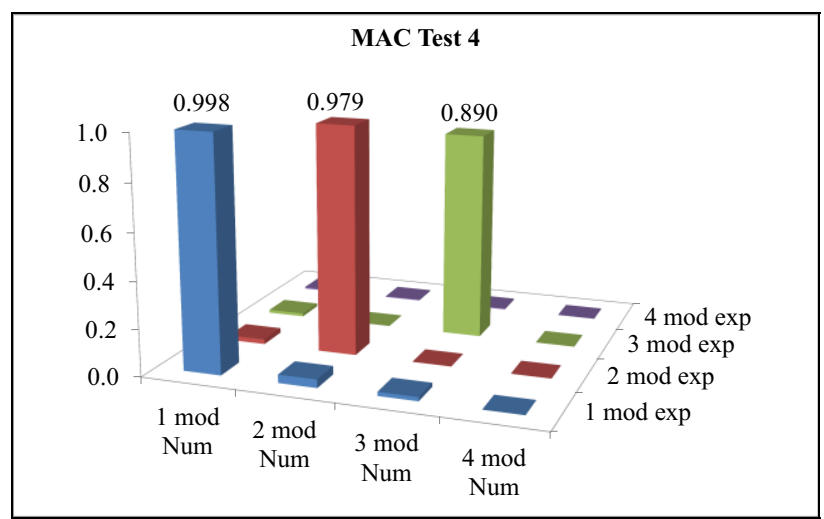

Figure 12. Modal assurance Criterion Test 4.

\subsection{Experimental tests with the TMD attached}

As it can be observed on Figure 4 the platform present high accelerations of about $3.0 \mathrm{~m} / \mathrm{s}^{2}$ that are out of the recommended limits by international codes [6]. To reduce acceleration a TMD was designed and installed at the slab center coinciding with the point of the highest first modal displacement. (Figure 1). The TMD vibrating mass is composed of several steel plates with $12,5 \mathrm{~mm}$ thickness, with several holes of $14 \mathrm{~mm}$ of diameter on its surface. The system stiffness is obtained through steel springs with coils of $2,5 \mathrm{~mm}$ of diameter and height of 65 $\mathrm{mm}$. The damping system is obtained with two vertical axes that generate dry friction with two small steel block.
Table 4 present TMD spring stiffness. The 10 springs were divided in two sets as it can be noticed in Figure 1. On Table 5 it is presented the weights obtained experimentally of each piece that constitute the vibrating mass of the TMD.

Table 4. TMD stiffness.

\begin{tabular}{|l|l|l|l|}
\hline \multicolumn{2}{|c|}{ Module 1 } & \multicolumn{2}{c|}{ Module 2 } \\
\hline Spring 1 & 5550.4 & Spring 6 & 5351.5 \\
\hline Spring 2 & 5130.2 & Spring 7 & 5296.6 \\
\hline Spring 3 & 5254.0 & Spring 8 & 5314.9 \\
\hline Spring 4 & 4957.6 & Spring 9 & 5249.1 \\
\hline Spring 5 & 4978.7 & Spring 10 & 5428.4 \\
\hline$\Sigma$ & \multicolumn{3}{|c|}{ K= 52511.4 N/m } \\
\hline
\end{tabular}

Table 5. TMD masses.

\begin{tabular}{|c|c|c|c|}
\hline \multicolumn{2}{|c|}{ Module 1 } & Module 2 \\
\hline Plate1+12 Rings & 5022.9 & Plate14+12 Rings & 4963.3 \\
\hline Plate 2 & 4880 & Plate 15 & 4820 \\
\hline Plate 3 & 4850.4 & Plate 16 & 4792.5 \\
\hline Plate 4 & 4792 & Plate 17 & 4795.7 \\
\hline Plate 5 & 4813.8 & Plate 18 & 4853.7 \\
\hline Plate 6 & 4784.8 & Plate 19 & 4738.8 \\
\hline Plate 7 & 4838.4 & Plate 20 & 4734.4 \\
\hline Plate 8 & 4878.7 & Plate 21 & 4882.1 \\
\hline Plate 9 & 4806.5 & Plate 22 & 4792.9 \\
\hline Plate 10 & 4878.7 & Plate 23 & 4860.6 \\
\hline Plate 11 & 4947.1 & Plate 24 & 4851.3 \\
\hline Plate 12 & 4726.5 & Plate 25 & 4826.5 \\
\hline Screw 1 & 203.9 & Screw 1 & 207 \\
\hline Screw 2+Piece & 801.6 & Screw 2+Piece & 786.7 \\
\hline Piece+ screw nut & 1036.2 & Piece+ screw nut & 1040.8 \\
\hline \multicolumn{3}{|c|}{ M = 120207.8 g } \\
\hline$\Sigma$ & \multicolumn{3}{|c}{}
\end{tabular}

From the above experimental parameters of mass and stiffness it is possible to calculate the TMD frequency:

$$
f=\frac{1}{2 \pi} \sqrt{\frac{K}{M}} \Rightarrow \frac{1}{2 \pi} \sqrt{\frac{52511.4 \mathrm{~kg} / \mathrm{s}^{2}}{120.2078 \mathrm{~kg}}}=3.33 \mathrm{~Hz}
$$

The experimental TMD natural frequency was obtained installing accelerometer on the vibrating mass and extracting a $20 \mathrm{~s}$ record. On Figure 13 on the frequency domain response it is possible to verify the TMD experimental frequency with a value of $3.516 \mathrm{~Hz}$. 


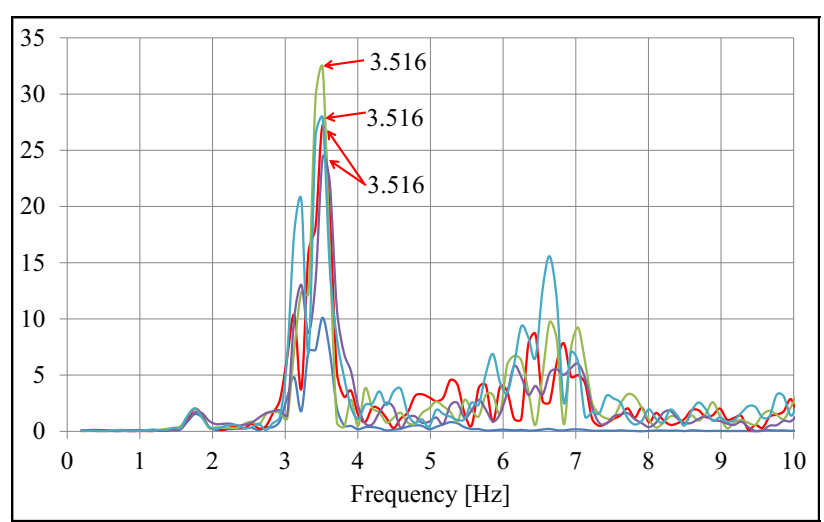

Figure 13. Frequency response of the TMD vibrating mass.

Having the above results of the TMD frequency $3,516 \mathrm{~Hz}$ and the main structure fundamental frequency of $3,32 \mathrm{~Hz}$ it was calculated the experimental frequency ratio $\beta$ that was about 1,059 . The mass ratio was calculated using the TMD vibrating mass $120.2 \mathrm{~kg}$ and the theoretical value of the slab mass, approximately $7173.6 \mathrm{~kg}$. With these mass values, the mass ratio was of $\mu=1.676 \%$.

The accelerometer installed on the TMD vibrating mass to find out the damper natural frequency is shown on a Figure 14.

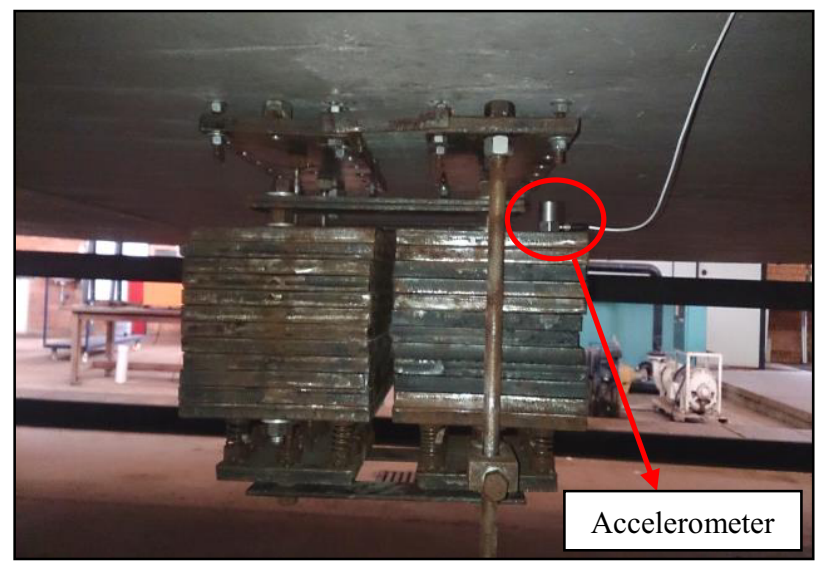

Figure 14. TMD installed with accelerometer 353B33.

\subsection{Experimental tests of rhythmic activities.}

With TMD tuned into a frequency near of the main structures resonance frequency and attached to the structure tests with rhythmic activities were performed to verify TMD performance. The tests were basically repeat several times a people or a group of people $(2,3,4$ and 5 people) walking synchronously or not for 20 seconds. It was also performed tests with a person jumping continuously at the center of the platform during 10 seconds and also groups of 3 and 5 individuals, distributed all over the slab. Synchronized tests with people with the knees semi flexed trying to simulate an harmonic force also were performed. As well it was simulated an impact force by a person jumping from a chair and letting the slab vibrate. It is noteworthy that all the tests were done the same way in a repetitive way, with coupled TMD and without TMD.
Thus records from different tests were compared to verify TMD performance. For the different tests three accelerometers were placed on the slab surface and a fourth accelerometer on the TMD vibrating mass. The accelerometers distribution can be seen on Figure 15 .

Figure 16 presents an acceleration time history when the structure is excited by an harmonic force of a person with semi flexed knees on the edge of the slab during 10 seconds, considering the without TMD situation (red line) and with the TMD attached (blue line). Figure 17 shows the corresponding frequency response.

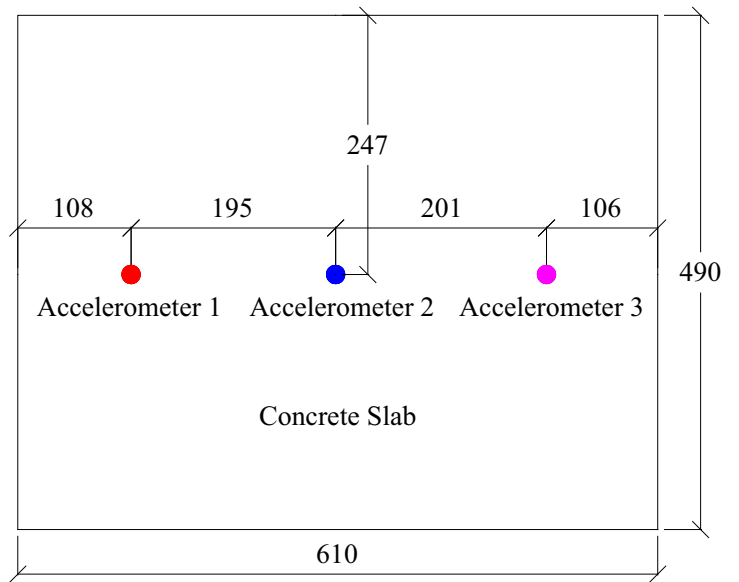

Figure 15. Accelerometer distribution $(\mathrm{cm})$

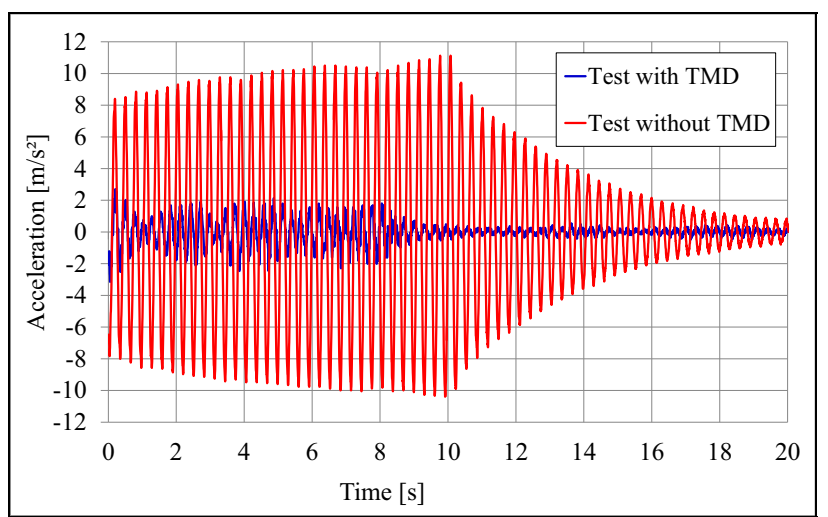

Figure 16. Acceleration time-history - with and without TMD semi flexed knees test.

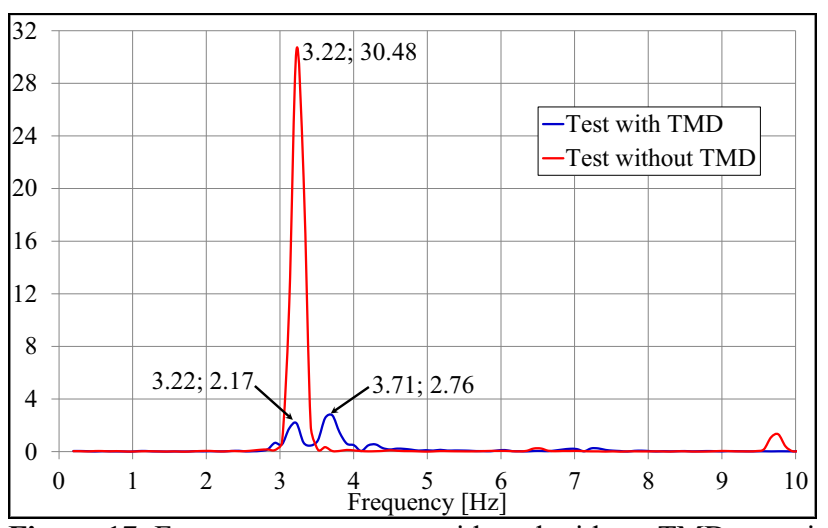

Figure 17. Frequency response - with and without TMD - semi flexed knees test. 
On the time domain analysis without TMD it can be observed that the maximum positive acceleration was of $11,13 \mathrm{~m} / \mathrm{s}^{2}$ and the maximum negative acceleration was of $-10,39 \mathrm{~m} / \mathrm{s}^{2}$, however for records with the TMD attached the maximum positive acceleration was of 2,70 $\mathrm{m} / \mathrm{s}^{2}$ and the maximum negative acceleration was of $-3,14$ $\mathrm{m} / \mathrm{s}^{2}$. For positive accelerations it represents a reduction of $75,74 \%$ and for negative accelerations a reduction of $69,78 \%$ installing the TMD on the platform. Verifying frequency response analysis it can be noticed that a reduction of about 11 times on vibration amplitude, about a $90,94 \%$ reduction and the appearance of a new structure natural frequency of $3,71 \mathrm{~Hz}$.

On the test simulating an harmonic force it can be said that the TMD reduces quickly the accelerations in less than 2 seconds after the appliance of the external load. Tests with continuous jumping of a person during 10 seconds on the center of the platform, results on time and frequency domains domain are presented on Figure 18 and Figure 19 respectively.

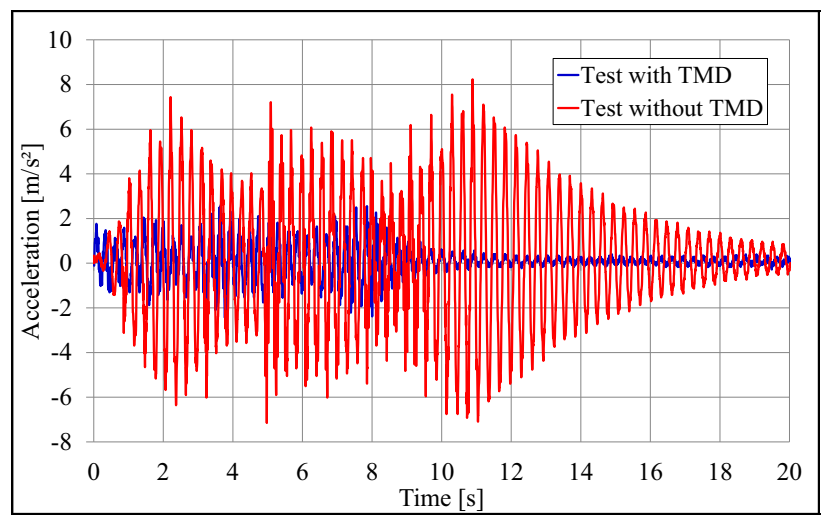

Figure 18. Time-Domain analysis with and without TMD continuous jumping during 10 seconds

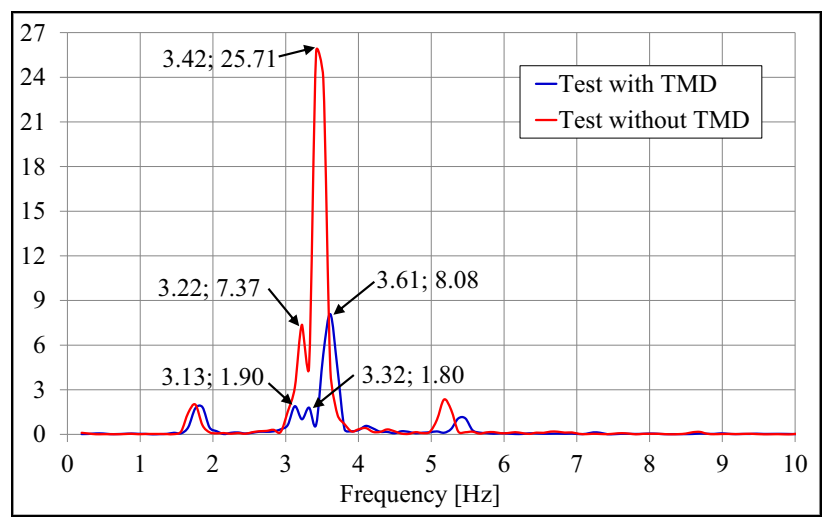

Figure 19. Frequency-Domain analysis with and without TMD. Continuous jumping during 10 seconds

On these tests it can also be observed a reduction on acceleration amplitudes records when the TMD is attached to the platform. On Figure 18 acceleration records in blue shows to be more regular due to the TMD action. Comparing Figure 16 with Figure 18 it can be said that the damper has a better performance to loadings more similar to harmonic force than those for nonuniform excitation forces like continuous jumping impacts In the same way of Figure 16 it can be observed that on Figure 18 after getting off the excitation force the TMD reduces accelerations a very low levels near to zero on a time interval of 2 seconds. In the case of the uncontrolled structures it takes about more than 9 seconds to the structure stop vibration. For continuous jumping tests of one person on the slab center Figure 19 also presents an amplitude vibration reduction of even 3,18 times, modifying the vibration frequency form $3,42 \mathrm{~Hz}$ to $3,61 \mathrm{~Hz}$. Other continuous jumping tests with groups of 3 and 5 people were performed as shown in Figure 20.

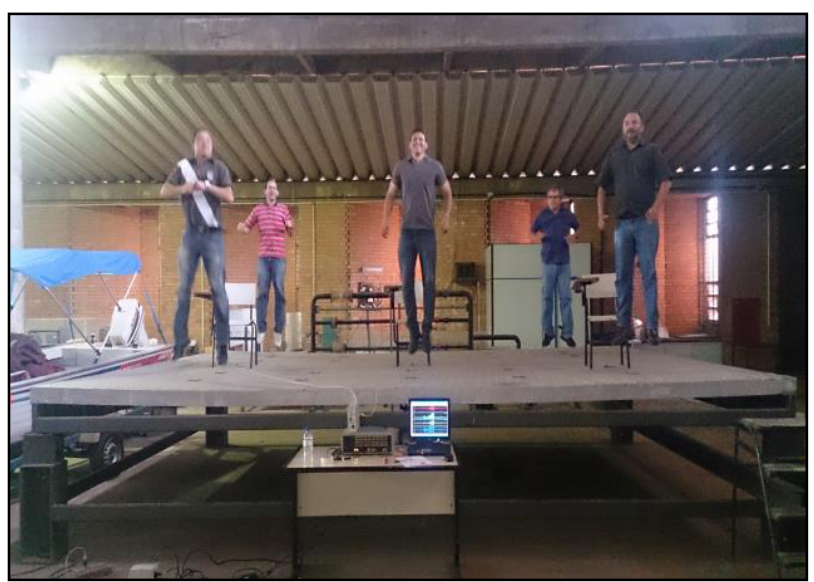

Figure 20. Continuous jumping tests with a 5 people group.

Tests with people walking all over the slab surface randomly during 20 seconds with $2,3,4$ and 5 people group were also performed. On Figure 21 and Figure 22, it is presented the time and frequency domain, respectively, for a group of 4 people walking randomly. Figure 23 show people walking randomly around the dynamic platform.

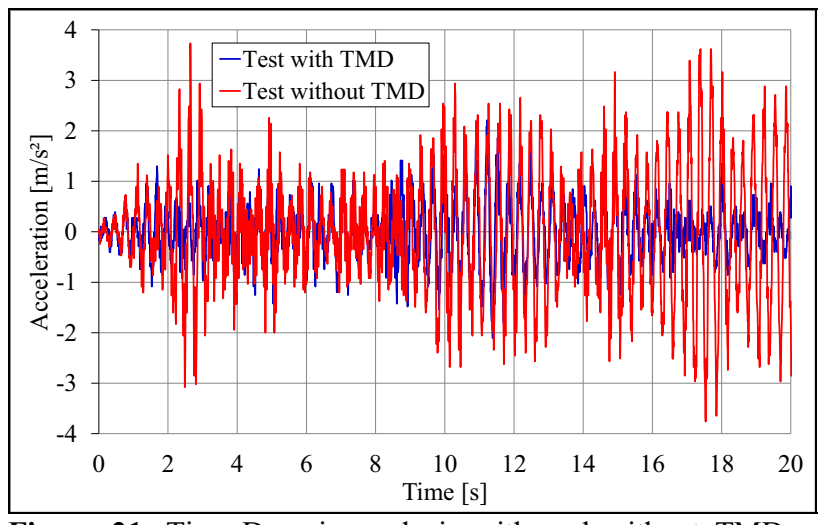

Figure 21. Time-Domain analysis with and without TMD walking test. 


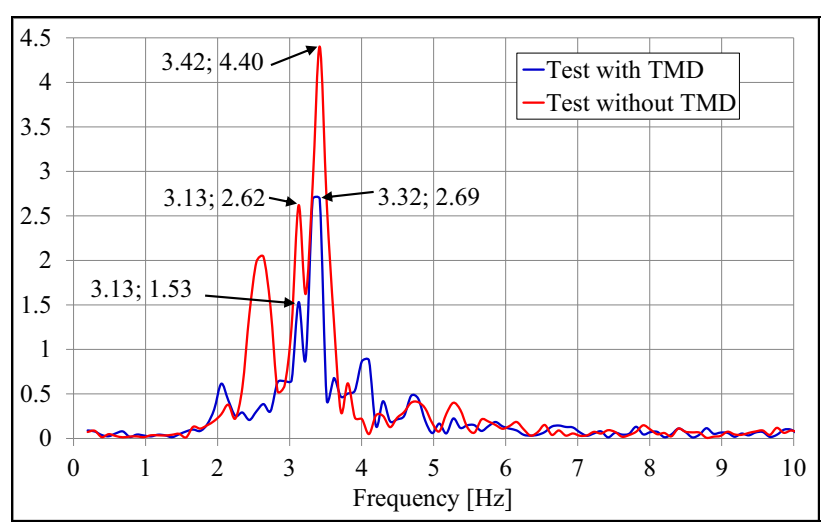

Figure 22. Frequency-Domain analysis with and without TMD - Walking test.

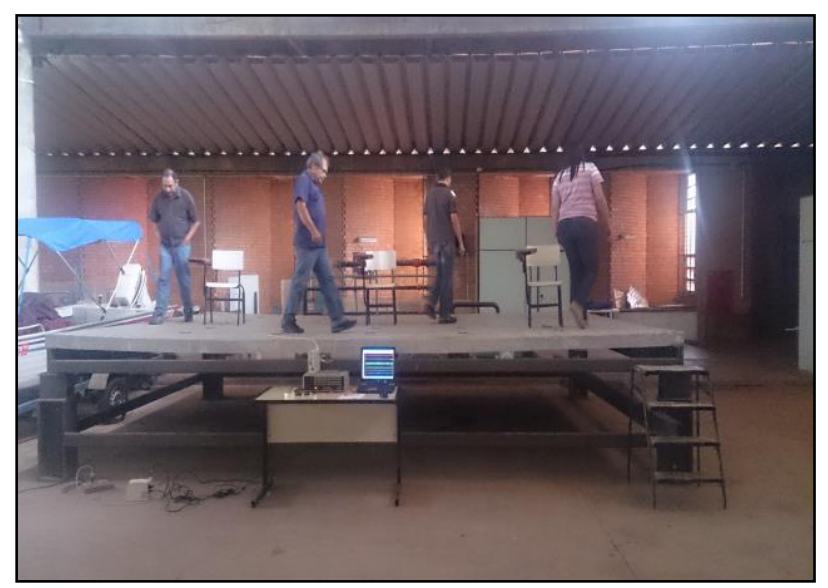

Figure 23. Test with people walking randomly.

From Figure 21 it can be observed that the damper performance is not so good like on the previous tests, however the TMD still reduces vibration amplitudes. On Figure 22 it can also be observed a response when using the TMD. Analyzing Figure 16 to Figure 22 it can be concluded that the damper presents a better performance on the harmonic loading case.

\subsection{Statistical analysis of experimental tests considering rhythmic activities.}

Results obtained from the above experimental program were analyzed through a statistical treatment. For repeating tests of continuous jumping with the TMD attached it was built an histogram of acceleration frequencies. Results for acceleration mean are presented on Figure 24. On Figure 25 it is presented results of the same tests without control. Comparing the graphs it can be observed that the histogram fifteenth class with control shows a great acceleration reduction from $11,93 \mathrm{~m} / \mathrm{s}^{2}$ without control to $2.87 \mathrm{~m} / \mathrm{s}^{2}$ with control, presenting almost the same percentage of acceleration mean of 0,02 $\%$. It can also be observed from the histogram with control that maximum percentage of acceleration is around of the mean value of $0,07 \mathrm{~m} / \mathrm{s}^{2}$, what represents a good reduction of acceleration records comparing the same test without control.

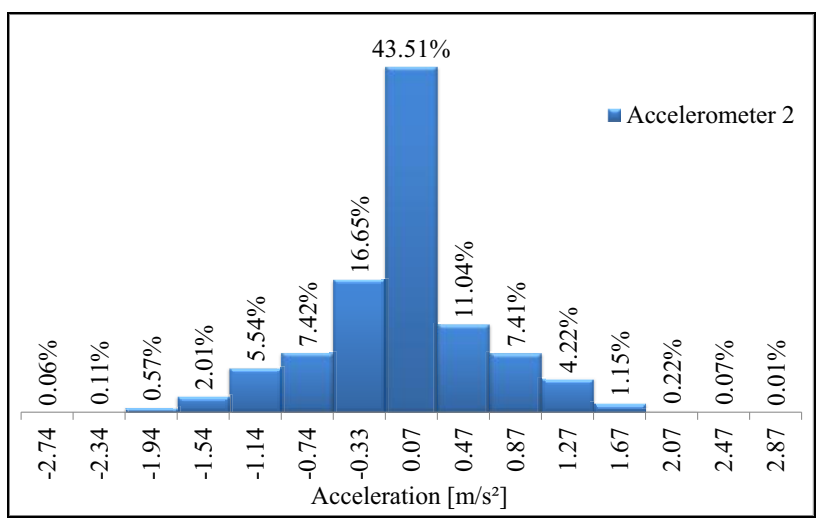

Figure 24. Acceleration relative frequency with TMD continuous jumping test 10 seconds

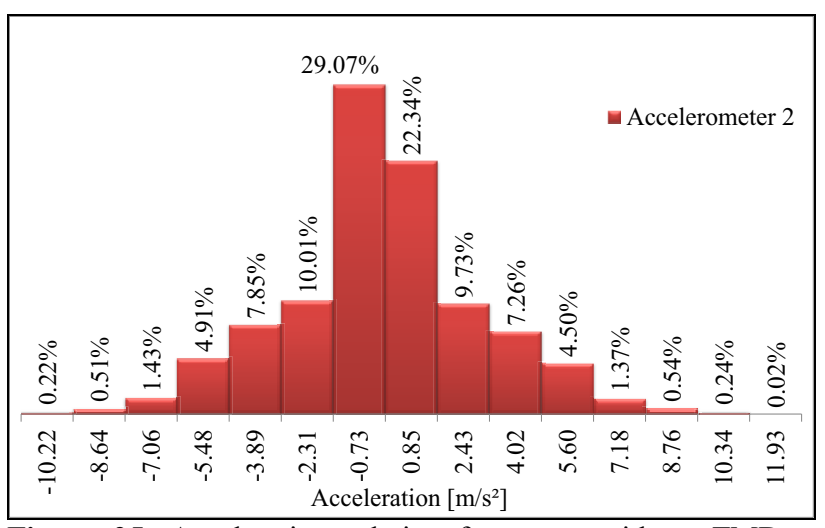

Figure 25. Acceleration relative frequency without TMD continuous jumping test 10 seconds

It is also presented on Figure 26 and Figure 27 the histogram of acceleration frequencies relative to accelerations obtained on tests of harmonic force simulation, with and without control, respectively. It can be observed that the control system reduces the response effectively, around $75 \%$ of the acceleration records are approximate to $0,22 \mathrm{~m} / \mathrm{s}^{2}$.

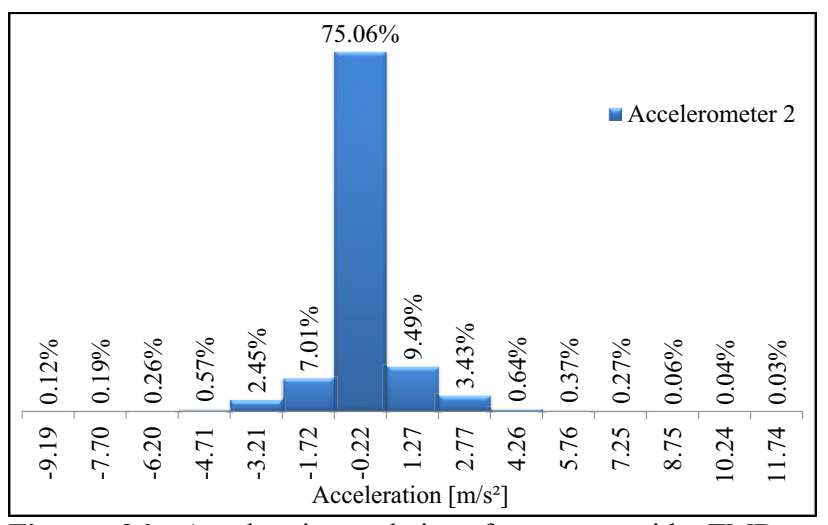

Figure 26. Acceleration relative frequency with TMD harmonic force. 


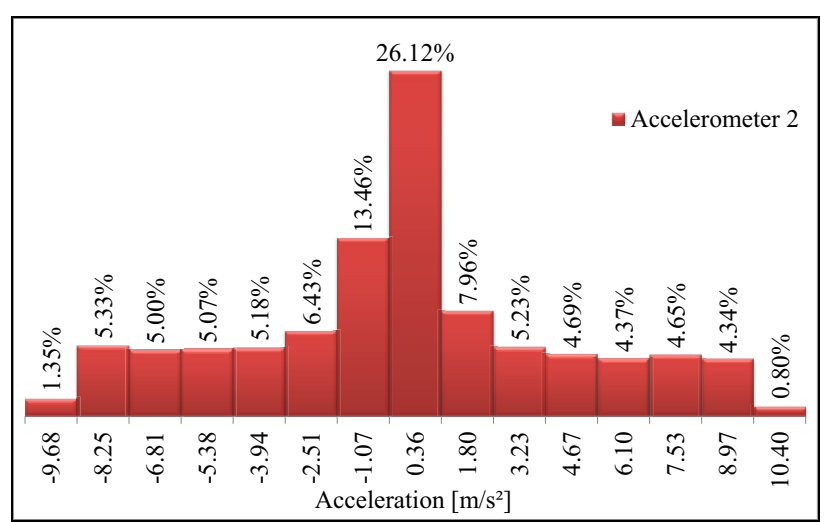

Figure 27. Acceleration relative frequency without TMD harmonic force.

On Figure 28 and Figure 29 it is presented the histogram of acceleration frequencies considering people walking randomly. There is a light reduction of the mean accelerations with control (blue histogram) comparing with mean acceleration without control (red histogram).

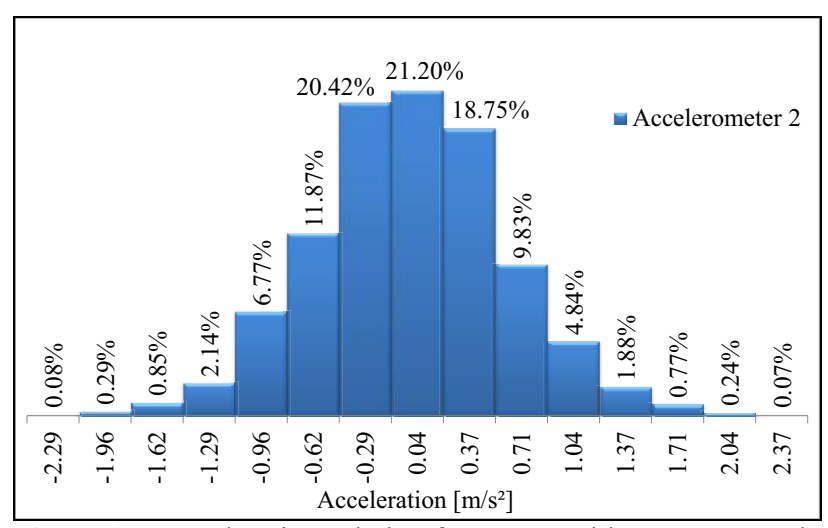

Figure 28. Acceleration relative frequency with TMD - people walking

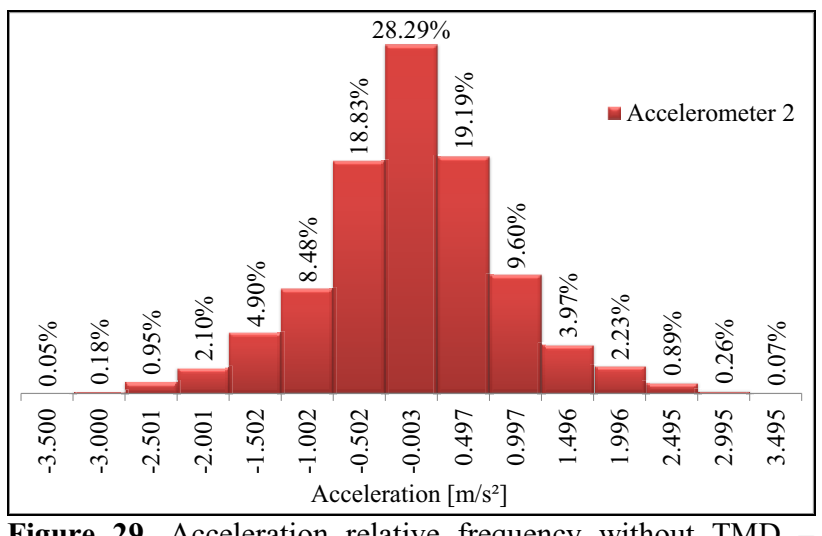

Figure 29. Acceleration relative frequency without TMD people walking

\section{Conclusions.}

A tuned mass damper was designed and then tested, it showed to be an effective structural control device on mitigating vibrations produced by harmonic forces on a concrete slab.

It also presents good performance reducing vibration caused by impact loads. It was observer that it worked better when the excitation force is greater that the induced force by people walking. The proposed TMD is characterized by its low cost of fabrication and it is also easy to build and maintain.

\section{References}

[1] GERB Schwingungsisolierungen GmbH \& Co. KG. Vibration Protection for Structures. Buildings. Machinery and other Equipment with Tuned Mass Dampers. (2001).

[2] Maurer Sönhe. Tuned Mass and Viscous Dampers. Technical information and products. Structural Protection Systems. 13 (2011).

[3] R.C. Battista, M. S. Pfeil. Control of Wind oscillations of Rio-Niterói bridge, Brazil. Proceedings of the Institution of Civil Engineers. ICE. Structures and Buildings 163 p 87-96. April (2010).

[4] ANSYS. Swanson Analysis System. Version 14.5. (2012).

[5] Campuzano. J.E., Doz. G. N., Avila. S.M. Study Design and Construction of a Tuned Mass Damper (TMD) For concrete building floors. Proceedings of the $9^{\text {th }}$ International Conference on Structural Dynamics, EURODYN. 1761-1768 (2014).

[6] Murray. T.M.. Allen. D.E.. Ungar. E.E. Floor Vibrations Due to Human Activity. Steel Design Guide Series. American Institute of Steel Construction. Second printing. October (2003).

[7] ARTeMIS modal 4.0 